\title{
Valuing and using web supported teaching: A staff development role in closing the gaps
}

Susan Shannon and Loene Doube

The University of Adelaide

This paper describes findings from a 2002-03 research project which sought to establish what the barriers were to the adoption or extended use of the centrally supported online learning management and content creation system by academic staff at the University of Adelaide. The research was conducted using semi-structured interviews and a survey administered to all teaching staff at the University. The survey canvassed respondents' use of and the value they placed on web supported teaching (particularly the centrally supported learning management system MyUni) and barriers to its adoption and further use. Respondents reported a higher valuing of and future intention to use than their current use of the Internet to support teaching. Factors that constrained their adoption or expanded use of web supported teaching included time and workload pressures, concerns about knowledge and skills, conceptions of teaching and the value of web supported learning for improving student outcomes, and the perceived stability and integration of the University infrastructure and learning management system. Respondents' views of priorities in addressing these management system. Respondents' views of priorities in addressing these
concerns related to improved support from the University for web supported teaching, including staff development and training, IT and administrative support, and management support. This paper discusses some staff development implications of the findings.

\section{Introduction}

Universities worldwide are devoting considerable resources to the development of web supported learning and teaching (AUTC, 2002). The degree of this development in Australian universities ranges from fully online courses to the use of the Internet to locate resources. Most higher education institutions in Australia have adopted a centralised learning management and delivery system, most prominently WebCT and Blackboard (Bell, Bush, Nicholson, O'Brien \& Tran, 2002). However, the manner in which such systems are deployed, and their use supported, is highly variable (McNaught, Phillips, Rossiter \& Winn, 2000). 
Despite claims (and evidence in some situations) of improved learning and teaching outcomes, increased flexibility and cost savings (DEETYA, 1998; Bell et al, 2002), many academics seem reluctant to adopt web supported teaching (Dearn, Fraser \& Ryan, 2002). Factors that have been seen to influence levels of adoption include:

- inadequate access to staff development and training (Dooley, 1999; Dooley, Metcalf \& Martinez, 1999; Lines, 2000; McNaught et al, 2000; Brennan, McFadden \& Law, 2001; Gruba, 2001; Oxford Brookes University, 2002; Scribbins, 2002; Guthrie, 2003)

- high workload (Dooley, 1999; McNaught et al, 2000; Brennan et al, 2001; Rumble, 2001; Oxford Brookes University, 2002; Scribbins, 2002)

- lack of time (Alexander \& McKenzie, 1998; Drysdale \& Creanor, 1998

Dooley et al, 1999; McNaught et al, 2000; Brennan et al, 2001; Gruba, 2001; Hansen \& Salter, 2001; Felix, 2002; Scribbins, 2002)

- lack of knowledge and skills (Salter \& Hansen, 1999; Breen, 2001; Brennan et al, 2001; Gruba, 2001; Hansen \& Salter, 2001; Scribbins, 2002)

- inadequate tools and infrastructure (Hansen \& Salter, 2001; Scribbins, 2002)

- lack of adequate recognition and rewards (Alexander \& McKenzie, 1998; Lines, 2000)

- conceptions of teaching and learning, including concern about the value of technology and the quality of learning and other student outcomes (Salter \& Hansen, 1999; Schifter, 2000; Brennan et al, 2001)

- inadequate other support from the institution, including IT support and support from management (McNaught et al, 2000; Guthrie, 2003)

The study reported here also found these factors to be barriers to adoption. However, the study also noted among respondents a gap between the (higher) value placed on the use of computers and the Internet to support teaching and the current (lower) use of these tools in teaching. Indeed most respondents were keen to extend their use of web supported teaching tools in the future. Personal motivation is commonly cited as a barrier to the use of web supported or computer facilitated teaching (McNaught et al, 2000; Schifter, 2000). In this study, while personal motivation may have inhibited attempts by respondents to overcome the identified barriers, it seems that their desire to use web supported teaching was high, a motivating factor that could be used to advantage in developing support strategies.

The responses of universities to overcoming barriers to the use of computers in teaching have included many different approaches to policy and strategy, quality assurance and evaluation, and staff development. However, Dearn et al (2002) note that, while there are many staff development programs available in the practice and theory of higher 
education, the majority of academic staff are reluctant to engage in them, and the provision of staff development in Australian higher education is 'uneven and unsystematic'. Other studies note a relative emphasis on training in the use of technology, at the expense of staff development that focuses on pedagogy and embedding technology use into teaching and learning practices (McNaught et al, 2000; Gruba, 2001).

Approaches to staff development and other support may be more successful if taking into account the positive intentions of teaching staff with regard to web supported teaching, and the value they place on the use of computers, the Internet and web based teaching. Based on the research findings, this paper discusses potential staff development approaches for a research intensive university such as the University of Adelaide. It reports findings from a 2002-03 research project which sought to establish:

- the use, knowledge and valuing of web supported teaching by teaching staff at the University of Adelaide

- barriers to their adoption or extended use of web supported teaching

- their future intentions and changes needed to encourage greater use of web supported teaching

\section{Background}

As one stage of an evolving set of strategies to provide an ongoing online education program at the University of Adelaide, Blackboard version 5.0 (Blackboard Inc 1997-2000) was piloted as an enterprise level online course development and delivery system in 2001. After evaluation of the pilot, Blackboard version 5.5.1 was adopted, and an online component (a course 'shell' without course material) was provided for all courses in Semester 1 , 2002. While every course had a 'shell', there was no requirement for teaching staff to use the online component of any course, although there was encouragement to do so (Ellis, 2002). The University named the centrally supported system MyUni, and promoted it to staff and students.

In Semester 2, 2002, 11\% of University of Adelaide courses had MyUni content in addition to that uploaded by the University administration. In Semester 1, 2003, this figure had risen to $16 \%$. The barriers to the uptake and extended use of web supported teaching identified in this research provide information about some of the reasons for low levels of uptake. The findings of the project led to a set of recommendations, many of which related to staff development strategies the University might consider, to minimise barriers to adoption and further use of web supported teaching. The focus of the paper is staff development responses that the University 
may adopt, taking into account the large proportion of respondents who would like to use web supported teaching, and the research intensive nature of the University of Adelaide.

\section{Methods}

\section{The survey}

The survey questionnaire was developed from the literature review and ten interviews conducted with staff from across the University of Adelaide. These staff were prominent either in their adoption of the pilot version of the centrally supported learning management system (MyUni) or in their use of another (parallel) system. The questionnaire was tested through administration to eight teaching staff from several faculties. The final questionnaire was shaped further by their responses.

The questionnaire included structured (fixed response and Likert scale) and open ended questions on topics including:

- respondents' teaching experience and use of computers and the Internet to support teaching

- respondents' attitudes to the use of computers and the Internet for teaching and students' learning

- factors that constrained the adoption or further use of web supported teaching tools

- future intentions in relation to the adoption or extension of web supported teaching

\section{The sample}

The target group for the survey was all teaching staff at the University of Adelaide. There were 999 tenured (or tenure track) full time and part time academic staff (persons) and 137 casual (full time equivalent) academic staff at the University in March 2002 (personal communication, Office of Planning and Development, May 2003). The questionnaire was distributed to the list of 1073 'instructors' registered in the MyUni database. Every course currently offered at the University has an entry in MyUni, and the instructors assigned to each course are the staff who have access to the course, and whose names are supplied to MyUni administration by the faculties. Thus the instructor list approximates a current list of teaching staff.

Consideration was given to distributing the questionnaire electronically, through email notification and a web link. However, there was concern that teaching staff who did not regularly access their email, and those who were not accustomed to linking to the University intranet, might not 
receive the questionnaire or might be discouraged from completing it. Therefore the questionnaire was sent by internal mail. There were 156 usable responses, a response rate of $14.5 \%$. The response rate was considered adequate for the purposes and resources of the project, and commensurate with another simultaneous whole of staff survey conducted centrally by the University's Surveys Office, and no follow up was done.

\section{Data analysis}

The data analysis, using SPSS version 11.5.0 (SPSS Inc., 2002), comprised descriptive statistics (means, standard deviations, frequencies, cross tabulations) and some tests for significance. Qualitative data from open ended questions were recorded and were also coded using categories derived initially from a sample of 15 questionnaires, and modified as coding progressed. After coding was complete, the initial categories were collapsed into fewer categories which identified broad issues for each question.

\section{Results}

\section{The sample}

The faculty distribution of survey respondents was approximately representative of the faculty distribution of academic staff. Eighty-four per cent of the respondents held full time positions, which was similar to the whole University figure of $86 \%$. There was a significant difference between the $69 \%$ of respondents who held tenured or tenure track positions and the overall University figure of $58 \%$. Females comprised $41 \%$ of the respondents, significantly higher than the $30 \%$ of University academic staff who were female. Most respondents taught undergraduate courses (96\%), and $42 \%$ taught postgraduate courses (generally as well as undergraduate courses). Compared with the University as a whole, the survey sample had an over representation of less experienced (in teaching) staff, as 35\% of all University of Adelaide academics had worked at the University for 10 years or fewer, whereas $62 \%$ of respondents had been teaching at a university for 10 years or fewer.

Thus, the sample had a higher proportion of tenured staff, women, and staff with less teaching experience than the University as a whole. Nevertheless, non-tenured staff, men and more experienced teachers were well represented in the sample.

\section{Current use of web supported teaching}

The questionnaire contained several questions concerning the extent of use of computers and the Internet in respondents' teaching. The variables were 
7-point Likert scales where 1 denoted 'nil' use of a computer related teaching tool, and 7 denoted 'a lot' of use (Table 1).

Table 1: Respondents' extent of computer and Internet use in teaching

\begin{tabular}{|l|c|c|c|c|c|c|}
\hline \multirow{2}{*}{} & \multicolumn{2}{|c|}{$\begin{array}{c}\text { Extent of } \\
\text { computer use }\end{array}$} & \multicolumn{2}{c|}{$\begin{array}{c}\text { Extent of } \\
\text { Internet use }\end{array}$} & \multicolumn{2}{c|}{$\begin{array}{c}\text { Extent of web } \\
\text { based teaching }\end{array}$} \\
\cline { 2 - 7 } & Frequency & Percent & Frequency & Percent & Frequency & Percent \\
\hline 1 Nil & 8 & 5.2 & 12 & 7.7 & 35 & 22.6 \\
\hline 2 & 18 & 11.7 & 24 & 15.4 & 29 & 18.7 \\
\hline 3 & 15 & 9.7 & 14 & 9.0 & 21 & 13.5 \\
\hline 4 Moderate & 17 & 11.0 & 31 & 19.9 & 16 & 10.3 \\
\hline 5 & 21 & 13.6 & 35 & 22.4 & 25 & 16.1 \\
\hline 6 & 24 & 15.6 & 17 & 10.9 & 14 & 9.0 \\
\hline 7 A lot & 51 & 33.1 & 23 & 14.7 & 15 & 9.7 \\
\hline Total & 154 & 100.0 & 156 & 100.0 & 155 & 100.0 \\
\hline
\end{tabular}

$\begin{array}{lll}\text { Notes: } & \text { Computer use: } & \text { missing cases }=2 ; \text { mean }=4.95, \mathrm{SD}=1.971 . \\ & \text { Internet use: } & \text { missing cases }=0 ; \text { mean }=4.26 ; \mathrm{SD}=1.828 .\end{array}$

Web based teaching: $\quad \begin{aligned} & \text { missing cases }=1 ; \text { mean }=3.45 ; \mathrm{SD}=2.007 \\ & \text {. }\end{aligned}$

It is noteworthy that $27 \%$ of respondents used computers in their teaching not at all, or to less than a moderate extent. There may be a wide range of definitions among respondents concerning what constitutes 'using computers in teaching', but this is unlikely to wholly account for the response. An even greater proportion of respondents $(32 \%)$ used the Internet to less than a moderate extent in their teaching, and a greater proportion again (55\%) said they had used web based teaching to less than a moderate extent. The greatest differences between computer use, Internet use and web based teaching were at the level of 'a lot' of use: $33 \%$ of respondents used computers a lot, $15 \%$ used the Internet a lot in their teaching, and 10\% had used web based teaching 'a lot'.

Among the respondents, $76.9 \%$ had used or were using web teaching tools. This level of use may not be representative of teaching staff as a whole at the University, since, in Semester 12003 , only $16 \%$ of all University of Adelaide courses had any MyUni content apart from that uploaded by University administrators. There were no significant differences in the use of web teaching tools among respondents on the measures faculty, tenure status, gender, or length of time respondents had taught at university. But full time employees were significantly more likely to have used these tools than part time employees.

When respondents were asked how much (on a scale of 1-7) they knew about MyUni, 26\% claimed to know less than a moderate amount, with five respondents saying they knew nothing at all. The mean was 4.65. 
Respondents were asked to indicate the years in which they had used web teaching tools (from 1995 to 2002), and the number of years they had been using them was calculated (Table 2).

Table 2: Number of years web teaching tools had been used and year use started (in brackets)

\begin{tabular}{|ll|c|c|}
\hline \multicolumn{2}{|c|}{ Years of use (used since) } & Frequency & Per cent \\
\hline 0 & (never used) & 36 & 24.0 \\
\hline 1 & $(2002)$ & 36 & 24.0 \\
\hline 2 & $(2001)$ & 18 & 12.0 \\
\hline 3 & $(2000)$ & 26 & 17.3 \\
\hline 4 & $(1999)$ & 17 & 11.3 \\
\hline 5 & $(1998)$ & 6 & 4.0 \\
\hline 6 & $(1997)$ & 4 & 2.7 \\
\hline 7 & $(1996)$ & 3 & 2.0 \\
\hline 8 or more & $(1995)$ & 4 & 2.7 \\
\hline \multicolumn{2}{|c|}{ Total } & 150 & 100.0 \\
\hline
\end{tabular}

Note: Missing cases $=6$.

Forty-eight per cent of all respondents had been using web teaching tools for one year or less, or not at all. Among the respondents who had used web teaching tools, $68 \%$ had been using them for longer than one year. The mean length of use among this group was 2.85 years. The centrally supported system, MyUni, became available for all courses taught at the University in 2002. Before 2002, tools available for web supported teaching included the MyUni pilot and an earlier central system, Adelaide University Online, as well as individual, school or department systems or web pages. Thus the majority of respondents had used one of these systems (see also Table 3)

Respondents who had used web teaching tools were asked what types of tools they had used, and teaching activities for which they had been used (Table 3). For each question a series of binary options were presented and respondents could select any number.

The majority had used MyUni, but many had also used other tools - 46\% had used the previously supported system Adelaide University Online, and around one-quarter had used their own or a departmental system. These, and the figures in Table 2, tend to suggest that many of the respondents who were MyUni users were early adopters who had previously used other web based teaching tools. The most common uses of web teaching tools were communication, including announcements, and delivering course content (Table 3). Administration of the course and assessment and groups administration had been used by less than half of 
the respondents. 'Other' uses included discussion groups and tutorials $(\mathrm{n}=12)$, and interactivity and multimedia $(\mathrm{n}=3)$.

Table 3: Web teaching tools and teaching activities used by respondents

\begin{tabular}{|c|c|c|}
\hline Tool used ${ }^{*}$ & Frequency & Per cent \\
\hline MyUni & 104 & 90.4 \\
\hline Adelaide University Online & 53 & 46.1 \\
\hline Own web pages & 31 & 25.8 \\
\hline Department provided system & 25 & 21.7 \\
\hline Faculty provided system & 12 & 10.4 \\
\hline Other University of Adelaide tools & 3 & 2.6 \\
\hline Other & 16 & 13.9 \\
\hline \multicolumn{3}{|l|}{ Teaching activity** $^{* *}$} \\
\hline Announcements & 95 & 83.3 \\
\hline Other communication & 93 & 81.6 \\
\hline Content delivery - lecture handouts & 95 & 83.3 \\
\hline Content delivery - whole lectures or topics & 61 & 53.5 \\
\hline Administration of course & 53 & 46.5 \\
\hline Assessment management & 36 & 31.6 \\
\hline Groups management & 28 & 24.6 \\
\hline Other & 23 & 20.4 \\
\hline
\end{tabular}

Thus, while the respondents who had used web teaching tools tended to be early adopters, they had also not commonly extended their use to the more interactive, complex uses of these tools.

\section{Valuing of web supported teaching}

Respondents were asked about the value they placed on computers and web teaching tools in higher education teaching (Table 4). The variables were 7-point Likert scales where 1 denoted 'no' value and 7 denoted 'very high' value.

The mean of the value the respondents placed on the use of computers in higher education (5.34) was higher than the mean of the value they placed on the use of web teaching tools (4.53). There was a large gap between the $76 \%$ of respondents who valued computers in tertiary education to more than a moderate extent, and the $54 \%$ who valued web teaching tools to more than a moderate extent.

More revealing is a comparison of the valuing of these tools with their actual use (see Table 1). The mean of the value respondents placed on computers in higher education (5.34) was higher than the mean for their use of computers in teaching (4.95). Only $13 \%$ of respondents valued 
computers in teaching to less than a moderate extent, while $27 \%$ used them to less than a moderate extent. The mean value placed by respondents on the use of web teaching tools in higher education (4.53) was also higher than the mean for their use (3.45). Twenty-eight per cent of respondents valued web teaching tools in higher education to less than a moderate extent, while 55\% used them to less than a moderate extent.

Table 4: The value respondents placed on computers and web teaching tools in higher education

\begin{tabular}{|l|c|c|c|c|}
\cline { 2 - 5 } & \multicolumn{2}{|c|}{$\begin{array}{c}\text { Value of computer } \\
\text { use* }\end{array}$} & \multicolumn{2}{c|}{$\begin{array}{c}\text { Value of web teaching } \\
\text { tool use }\end{array}$} \\
\cline { 2 - 5 } & Frequency & Per cent & Frequency & Per cent \\
\hline 1 None & 1 & 0.6 & 3 & 2.0 \\
\hline 2 & 10 & 6.5 & 18 & 12.0 \\
\hline 3 & 9 & 5.8 & 21 & 14.0 \\
\hline 4 Moderate & 17 & 11.0 & 27 & 18.0 \\
\hline 5 & 38 & 24.7 & 36 & 24.0 \\
\hline 6 & 36 & 23.4 & 26 & 17.3 \\
\hline 7 Very high & 43 & 27.9 & 19 & 12.7 \\
\hline Total & $\mathbf{1 5 4}$ & $\mathbf{1 0 0 . 0}$ & $\mathbf{1 5 0}$ & $\mathbf{1 0 0 . 0}$ \\
\hline Notes: ${ }^{*}$ missing cases=2; mean $=5.34 ;$ SD $=1.510$ \\
\end{tabular}

\section{Intended future use of web supported teaching}

Respondents' future intentions with regard to using web teaching tools were canvassed and two choices were coded (Table 5).

Table 5: Respondents' future intentions for use of web teaching tools

\begin{tabular}{|l|r|r|r|r|}
\hline & \multicolumn{2}{|c|}{ First choice $^{*}$} & \multicolumn{2}{c|}{ Second choice $^{* *}$} \\
\cline { 2 - 5 } & Frequency & Per cent & Frequency & Per cent \\
\hline Use University platform (MyUni) & 132 & 88.0 & 1 & 2.3 \\
\hline Use other web teaching tools & 5 & 3.3 & 38 & 88.4 \\
\hline Never use web teaching tools & 5 & 3.3 & 0 & 0.0 \\
\hline Other & 8 & 5.4 & 4 & 9.3 \\
\hline Total $\quad{ }^{*}$ missing cases =6 & $\mathbf{1 5 0}$ & $\mathbf{1 0 0 . 0}$ & $\mathbf{4 3}$ & $\mathbf{1 0 0 . 0}$ \\
\hline Notes: ${ }^{* *}$ missing cases =113. & \multicolumn{4}{|l}{} \\
\end{tabular}

Eighty-eight per cent of respondents indicated for their first choice that they would use MyUni in the future for web supported teaching. Among the respondents who had not used web teaching tools, $74 \%$ said they would use MyUni in the future. Thirty-one per cent of all respondents said they intended to use other web teaching tools, either in addition to MyUni or instead, including three from the 'other' responses who said they would 
'Use department/school web pages or system'. For the whole sample there were 10 respondents $(7 \%)$ who, for their first choice, did not intend to use some kind of web teaching tool in the future (including five respondents for 'other').

Respondents were asked what teaching or related activities they would like to be able to do with MyUni. Up to three comments were coded. Sixtysix respondents $(42.3 \%)$ commented, giving 86 responses (Table 6).

Table 6: Teaching or related activities respondents would like to be able to do (or do differently) with MyUni

\begin{tabular}{|l|c|c|}
\hline \multicolumn{1}{|c|}{ Comment category } & Frequency & Per cent \\
\hline Features / uses & & \\
\hline More advanced features / activities & 41 & 47.7 \\
\hline $\begin{array}{l}\text { Currently available basic activities (basic } \\
\text { communication, content delivery) }\end{array}$ & 16 & 18.6 \\
\hline Course administration, management, evaluation & 7 & 8.1 \\
\hline Would like no change & 4 & 4.7 \\
\hline$\quad$ Use for particular students or courses & 2 & 2.3 \\
\hline Perceptions & & \\
\hline$\quad$ Negative perceptions of MyUni & 8 & 9.3 \\
\hline A new teaching challenge & 2 & 2.3 \\
\hline Other & & \\
\hline Don't know & 5 & 5.8 \\
\hline Other & 1 & 1.2 \\
\hline Total & $\mathbf{8 6}$ & $\mathbf{1 0 0 . 0}$ \\
\hline
\end{tabular}

The most common open comments concerned respondents' desire to do more 'advanced' activities which they had not yet done themselves or which they perceived could currently not be done with MyUni: these related principally to the assessment capacity of MyUni $(n=17)$, to other interactive features such as discussion groups and multimedia $(n=20)$, and to course administration matters $(n=7)$ :

The ability to somehow put software - Java applications? Microsoft applications? - onto the [MyUni] web site would be beneficial. Can this be done?

I would like to have assessment questions in MyUni to which seamless, password controlled access is available, with the ability to return to the password controlled access is available, with the ability to return to the
external text clearly pathed at the MyUni end (and customisable there).

Have more discussion to broaden student experiences.

Thus, while some respondents would like to use the more basic MyUni features, many respondents were keen to extend their use to more advanced features, and in some instances also to see the capacity of MyUni 
extended. It is also clear that many respondents were not fully aware of the current functionality of MyUni. Some respondents used the opportunity for comment to convey negative perceptions about the MyUni system.

\section{Barriers to adoption and further use of web supported teaching}

Respondents who had not used web teaching tools were asked to comment on what needed to change so that they would use them. Some respondents who had used web teaching tools also answered this question, and their responses were included to enrich the qualitative data. Up to three comments were coded, from 58 respondents (37\%), giving 98 responses. All respondents were asked to comment on what needed to change so that they would use the University's centrally supported system, MyUni. For current users, this was interpreted as what needed to change so that they would use MyUni more or differently. Up to three comments were coded, from 67 respondents $(43 \%)$, giving 96 responses. Table 7 presents the responses for the two questions.

Table 7: Changes needed so that respondents would use web teaching tools or MyUni or use them more or differently

\begin{tabular}{|l|r|r|r|r|}
\hline \multirow{2}{*}{ Comment category } & \multicolumn{2}{|c|}{ Web teaching tools } & \multicolumn{2}{c|}{ MyUni } \\
\cline { 2 - 5 } & Frequency & $\%$ & Frequency & $\%$ \\
\hline Individual factors & & & & \\
\hline Workload / time & 25 & 25.5 & 17 & 17.7 \\
\hline$\quad$ Skills / knowledge & 5 & 5.1 & 4 & 4.2 \\
\hline Support & 7 & 7.1 & 23 & 24.0 \\
\hline$\quad$ Tools / web based teaching system & 8 & 8.2 & 13 & 13.5 \\
\hline $\begin{array}{l}\text { Infrastructure / integration } \\
\text { (including for students) }\end{array}$ & 15 & 15.3 & 9 & 9.4 \\
\hline Training / staff development & 10 & 10.2 & 4 & 4.2 \\
\hline Other support & 5 & 5.1 & 4 & 4.2 \\
\hline Policy / management support & & & & \\
\hline Conceptions of learning and teaching & 14 & 10.2 & 6 & 6.3 \\
\hline$\quad$ Quality/ benefits/outcomes concerns & & & & \\
\hline Other & 4 & 4.1 & 2 & 2.1 \\
\hline $\begin{array}{l}\text { Students (excluding infrastructure, } \\
\text { access) }\end{array}$ & 2 & 2.0 & 2 & 2.1 \\
\hline Copyright & 2 & 2.0 & 7 & 7.3 \\
\hline Other & 1 & 1.0 & 5 & 5.2 \\
\hline Don't know & $\mathbf{9 8}$ & $\mathbf{1 0 0 . 0}$ & $\mathbf{9 6}$ & $\mathbf{1 0 0 . 0}$ \\
\hline Total & & & & \\
\hline
\end{tabular}

The individual concern most frequently mentioned was time and workload, although this was more common in relation to the uptake of web teaching tools than in relation to the use of MyUni. Respondents 
mentioned both lack of time due to other responsibilities, and the perceived extra time needed to learn about and develop web supported teaching:

Time pressures make it very difficult to be able to:

(a) acquire the necessary skills to do a good job

(b) invest the extra time needed to prepare good quality materials.

Delivering materials / courses online takes a lot more time for the facilitator. My experience has been that institutions see web based learning as a cost reduction strategy. It actually costs more - materials have to be of higher quality, it takes more facilitation time and requires more frequent updating.

It [web based teaching] needs to be presented in a better manner which requires far less investment of staff \& student time to achieve gains.

I think I could make good use of MyUni in my teaching but I would need to be free to put my time and energy into learning how to use it and then reconceptualising my curriculum to make it effective in MyUni.

Release time to learn about it and think about ways to use it effectively.

Half of the comments related to aspects of support that the University could provide, most prominently concerning the MyUni system or other tools and the University infrastructure:

Spreadsheet editing in online gradebook unacceptably slow!

I have fully established web based teaching units. The installation of MyUni is an excellent base for course organisation but is limited for web based teaching material.

All current access problems, course merging, understanding that e.g.

[Campus name] does exist, does teach out of semester, does teach as many external as internal students - must be fixed.

The need for support from IT services, department or University was also commonly expressed, in this case more commonly in relation to the use of web teaching tools:

It will not work unless schools have local IT people to assist staff with software and hardware problems.

I do use web teaching tools, but I think there needs to be more support \& understanding \& foresight from management.

I need IT and admin support because web based teaching can be more resource intensive.

Active support of department. 
Another common support issue was the need for staff development / training and a related concern about lack of skills / knowledge, especially in relation to the use of web teaching tools, probably reflecting the higher proportion of respondents who had not used web teaching tools at all in this group.

I would use MyUni more if ... I had more training/information on what the good things are about it. Workshops with like minded colleagues would help.

I would really like to have workshop etc where other staff from other areas / faculties can show us how they used MyUni.

I realise that IT runs training sessions but during semester, trying to find a whole morning or a day is just not easy. Perhaps a few shorter in house sessions may be useful.

I need to know more about it; I am ignorant of what else is going on.

Twenty comments expressed particular conceptions of teaching or concern about the quality of learning that can be achieved using web support, again more commonly in relation to the use of web teaching tools, and more likely to have come from non-users of such tools:

I need to be convinced that [web teaching tools] contribute a real advance. So far no one has done this.

It would need to become a higher priority than all other things we are expected to do, or produce significant benefits over existing methods.

My topics are not suitable for online assessment. Students require mentoring and guidance not rote learning.

I do not believe in web based teaching. Things do not have to be done simply because they can be done. Nothing can replace the direct contact between teachers and students.

\section{Discussion: Closing the gaps}

The survey was conducted one year after the introduction of MyUni for all courses at the University of Adelaide. The respondents, all teaching academics at the University, represented both staff who had used web supported teaching and those who had not. The group of respondents who had used web teaching tools ( $77 \%$ of the total) appeared to be early adopters of web supported teaching, but by the time of the survey in February 2003 their use tended to be mainly for communication and content delivery. There was lower use of the more interactive, advanced uses of these tools. Other researchers have noted similar findings; for example, Brennan et al (2001, p. 22) noted that technology in higher 
education was being used mainly 'for searching, for communicating, for providing information, and for processing text in various forms - not for full online delivery'.

The respondents in general valued the use of computers and the web in teaching more than they actually used them, and most intended to use web supported teaching in the future. Commonly, respondents were keen to adopt or increase their use of the centrally supported platform, MyUni, to more of the basic features or to more advanced, interactive uses, particularly in relation to assessment and assessment management. Onethird of respondents intended to use other tools, in addition to or instead of MyUni. If this figure is indicative of teaching staff as a whole at the University, it indicates the need for staff development and other support for staff using other systems. It also indicates a need for the University to explore means to remove the barriers to the adoption of the central system. From respondents' comments, important perceived areas of change for this group are the functionality of MyUni and the IT infrastructure of the University. Others have also found that the demand for and expectations of IT infrastructure 'are constantly outstripping supply' (McNaught et al, 2000; Scribbins, 2002). Breen (2001) found that the infrastructure at Oxford Brookes University was not keeping up with the developments taking place in web based learning.

The barriers to respondents' adopting web supported teaching or using it to a greater extent were dominated by the perceived need for more support, whether expressed directly or implied in comments about time and workload or skills and knowledge. Barriers also included conceptions of teaching and concerns about the quality of the learning and teaching possible using the Internet as a support. Time and workload and knowledge and skills are commonly cited as barriers to the adoption or further use of web supported or computer facilitated teaching. Scribbins (2002), for example, found instances of staff in the further education sector in the United Kingdom not having time to learn the new skills required to use information \& learning technologies. Gruba (2001), Scribbins (2002) and Hansen and Salter (2001) found lack of knowledge and skills to be important inhibitors of the uptake of web supported or computer facilitated teaching. Conceptions of teaching and doubt about the quality of learning that can be achieved using the Internet as a support are also commonly found to be barriers. The increasing emphasis on learner centred approaches and processes of education that is encouraged by online learning is uncomfortable for many teachers (Schifter, 2000); teachers are concerned about loss of work and that their roles are under scrutiny (Brennan et al, 2001); academics are concerned about the effectiveness of online delivery, of itself and in comparison with face to 
face teaching (Salter \& Hansen, 1999; Gruba, 2001). Thus, the literature indicates that the concerns felt by the respondents are likely to be widely felt among staff at the University of Adelaide.

The gaps identified in this study between the value placed on and the actual use of computers and the Internet to support teaching, and the professed desire of most respondents to use web supported teaching to a greater extent indicate that their potential motivation was high, but was being constrained by the identified barriers. If this finding is indicative of the University as a whole then strategies to increase personal motivation may not be as important as they have been reported to be in previous studies (for example, McNaught et al, 2000; Schifter, 2000). McNaught et al (2000) and Oxford Brookes University (2002), however, did note lack of time or increased workload as a reason given for non-adoption even if staff were otherwise motivated.

To encourage broader use of web supported teaching and learning at the University, additional and/or more accessible support strategies are needed to alleviate staff concerns. The findings suggest the need for staff development support for a variety of levels of web supported teaching, from support aimed to attract and inform non-users, through staff development and training in basic uses and the pedagogy of using web teaching tools, to staff development and training for more advanced, interactive and administrative, uses of web supported teaching. Evidence of lack of adequate access to existing staff development, and the prevalence of time and workload issues as barriers, suggest the need for more flexible arrangements for staff development opportunities.

\section{Staff development to encourage web supported teaching}

Many studies find lack of staff development (or inadequate access to it) to be a major issue retarding the uptake and successful use of information technologies to support learning and teaching (for example, Lines, 2000 McNaught et al, 2000; Scribbins, 2002; Guthrie, 2003). Adequate preparation of academic staff for a teaching role is no longer a voluntary matter: the new quality assurance framework for Australian universities requires that they be able to demonstrate the ways in which they ensure the quality of learning and teaching in their organisations (Gribble \& Ziguras, 2003).

All universities provide staff development, and there is a wide variety of approaches to it in relation to the pedagogy and skills of web supported teaching, and in relation to managing the changes that are required for staff to adopt 'the new technologies' in their teaching. The University of Adelaide has policies and strategies in place to encourage web supported 
teaching and learning. However, the findings of this study indicate that many staff at the University do not have adequate access to the currently available support. Most staff development for teaching at the University of Adelaide is provided by a central unit, the Learning and Teaching Development Unit (LTDU). Apart from a foundation Teaching at University course for new academic staff, which includes a unit on online teaching and an introductory workshop on using MyUni, staff development for teaching is not compulsory, and staff development activities are not accredited as part of a formal qualification.

Most teacher development is provided through one off workshops and training sessions, which can be provided in a central location across disciplines, or in a discipline setting (often by request from a school or faculty). In 2002 the LTDU provided training in the basic and advanced features of MyUni to 205 staff (less than 20\% of all University academics) and pedagogical support for web supported learning and teaching was provided by a website devoted to online education (Learning and Teaching Development Unit, 2003). Other staff development was provided to 108 staff through faculty based workshops and the Teaching at University course (LTDU, 2003). This seems to be a similar situation to that at most other Australian universities, where preparation of staff for teaching is 'largely unsystematic and ad hoc' and participation is low (Dearn et al, 2002).

\section{Shaping staff development}

The findings of the current study suggest the need for improved staff development support and improved access to staff development for a variety of levels and types of web supported teaching. Reid (2002) also found that different types of support were needed, 'for individuals at all levels, for teams of people, for learning how to use new technologies'. Other researchers also recommend approaches based on the needs of different users (for example, Dooley, 1999; Hansen, 2001; Hansen \& Salter, 2001).

Several different approaches to embedding learning technologies into higher education teaching and learning are revealed in the literature. Most involve institution wide support for professional development, with varying models recommended or shown to be effective in certain circumstances. These models have much in common, such as the need for collaboration and consultation, a combination of top down and bottom up strategies, and the need for a variety of staff development initiatives to meet different and changing needs. 
Dearn et al (2002) see the professionalisation of teaching in higher education to be the key to improving university teaching. They recommend several staff development initiatives to foster this professionalisation:

- $\quad$ required formal, accredited teacher preparation for new higher education teachers

- $\quad$ support for existing staff to undertake an award course in teaching

- that sessional staff be expected to undertake 'a minimal level' of teaching preparation

- $\quad$ ongoing professional development 'as part of the overall quality assurance system for Australian higher education' (Dearn et al 2002, p. vi)

Reid (2002) concludes that, while there are many effective approaches to staff development, 'a focus on conceptual change related to teaching and learning within a specific discipline context, whatever the approach, is important'. O'Hagan (1999) also suggests that embedding technology in learning and teaching must be mediated through the 'local change environment

Reid (2002) reviews several models for the delivery of staff development and recommends an integrated model, based on a theory of conceptual change (in regard to teaching). In this model, staff developers from central units and academic teachers in departments collaborate to provide appropriate staff development in teaching for all levels of need in any department. Departments eventually assume responsibility for conceptual change that leads to teaching development, while still receiving support from the central staff development unit. A key to the effectiveness and acceptance by teaching staff of this approach is that it is developed in consultation with departmental managers. It is thus likely to be aligned with the department and the university's strategic directions. Dooley (1999) emphasises the effectiveness of consulting teachers about their staff development and other needs in relation to the adoption of technological innovations. Staff development opportunities that build on staff's intention to use web supported teaching would seem appropriate in this context.

Using an integrated model, particular activities and approaches to their delivery can fall within the widest range possible: they show 'a fluidity of application' (Reid, 2002), but are based on the premise of changing academics' conceptions of teaching. In relation to web supported teaching this would involve embedding the use of technology into teaching and the curriculum at all levels (McNaught et al, 2000). The findings of this study 
indicate that it would also involve an institution wide approach and institutional support to meet the needs of:

- staff at different levels of adoption

- different faculties, departments, disciplines and campuses

- new teaching staff

- casual and contract staff

It is also clear from the findings that teaching staff do not adequately access currently available opportunities for staff development. It would be beneficial using an integrated model to provide a greater variety of opportunities for staff development and training, and provide a greater variety of local and central activities; for example, short, specific workshops, refresher courses before the beginning of semester, sharing of experiences and mentoring from staff who have used web supported teaching, provision of templates with built in guidelines for the creation of educationally sound content.

\section{A research base for staff development}

Greater variety of staff development opportunities alone is unlikely to induce overworked and time poor staff to attend. The University also needs to further develop policies and strategies to integrate staff development across the organisation, and to provide incentives and support for staff to attend. Time release and local management support are necessary incentives, but an approach that takes advantage of what academics in a research intensive university value is likely to receive their attention. The success of an integrated conceptual change focussed approach, in Reid's (2002) view, also requires that:

The scholarly nature of the work involved in developing quality in teaching and learning needs to be recognised as legitimate academic work. (Reid, 2002, p. 9)

At a research intensive, Group of Eight (GO8) university, the value of formal or informal teaching qualifications and the overall valuing of 'teaching' as an academic activity are generally subsumed to a valuing of research. In a survey of values at the University of Adelaide conducted in January 2003 (Sarris, Taplin \& Reilly, 2003), the respondents' (18\% of University staff) assessment of the characteristics that distinguished the University of Adelaide from other universities in South Australia and elsewhere did not include teaching and learning. While teaching was not mentioned in relation to this question, when respondents were asked what they thought the key values of the University should be in the future, their 
most prominent response was 'continuing to achieve excellence in research, teaching and innovation'.

In a research intensive university, where research informs teaching, a research base for web supported teaching is likely to be valued. Kearns (2003) endorses a research focus to extend the role of information and communication technologies in education. He suggests 'Strengthening and focussing the research and development role and linking this more closely to policy and practice' (Kearns, 2003, p. 45) as one of four strategies to achieve this purpose. Reid (2002, citing Fletcher \& Patrick, 1998) also refers to calls for 'research on the impact of teaching strategies for student learning' to lead to a change in academic culture in terms of teacher related activities.

A larger body of research evidence for the academic benefits of web supported teaching and learning for staff and students is needed. Since academic staff find time for the activities they value, promotion of such research may influence staff to adopt or extend their use of web supported teaching from an evidence base. In this context, three types of staff development are suggested, to encourage:

- the adoption of web supported teaching - research evidence of the benefits to students' learning outcomes and staff management of online course administration

- the continued use of web supported teaching - evidence from evaluation of student responses, used formatively, with reflection and response to evaluation supported by discipline based staff development in embedding technology in teaching and learning

- the development and extension of web supported teaching to more sophisticated and interactive modes - structured online and face to face support to relieve staff of the necessity of 'doing it themselves'

\section{Conclusion}

The suggestions developed from the findings and taking into account the research intensive context of the University of Adelaide include staff development for web supported teaching that is:

- based on the ascertained needs of teaching staff at all levels of adoption

- integrated with the directions of departments and the University

- integrated to provide for incremental development of teachers' capacity in web supported teaching

- offered flexibly and in a variety of modes 
- informed by ongoing research of staff developers and discipline based academics

Further detailed research is suggested to inform specific implementations of these suggestions:

- in faculty and discipline contexts

- for staff who use alternative systems to MyUni

- for subgroups such as casual and part time staff

- for staff at different levels of adoption of web supported teaching

For example, while it is clear that staff who have never used web supported teaching need time / workload release to encourage their adoption, and users of web based teaching tools need better tools and infrastructure and better understanding of existing tools to encourage extended use, more research is needed to clarify the needs of these two groups and the means of meeting them within the budgetary constraints and the cultural setting of the University.

The current study was limited by the small size of the sample, the high proportion of respondents who were current users of web teaching tools (when a low proportion of staff as a whole used them), the difference between the sample and the academic cohort in some key areas (tenure, sex and teaching experience), and the lack of resources to do further analysis of the data. In addition, the centrally supported universal online learning management system, MyUni, had been available for only one year when the survey was conducted, and the Learning and Teaching Development Unit was in the early stages of developing an online learning and teaching program. Further research in two or three years at the University of Adelaide would enable useful comparison of the current findings with the situation after the anticipated growth in adoption. Such an approach would avoid many of the variables that exist in crossinstitutional comparisons.

\section{Acknowledgement}

Some of the tests for significance were conducted by John Petkov, Applied Mathematics, The University of South Australia, Whyalla Campus.

This research was funded by a University Learning and Teaching Development Grant 2002 awarded to Susan Shannon by the Deputy ViceChancellor and Provost to promote the enhancement of learning and teaching at the University of Adelaide. 


\section{References}

Alexander, S. \& McKenzie, J. (1998). An evaluation of information technology projects for university learning (executive summary), Canberra, Committee for University Teaching and Staff Development (CUTSD).

http: / / www.dest.gov.au/archive/cutsd/publications / exsummary.html

AUTC (Australian Universities Teaching Committee) (2002). The centrality of learning. Higher Education Review Submission 10, Canberra, Department of Education, Science and Training.

http:/ / www.backingaustraliasfuture.gov.au/submissions/crossroads/pdf]/10.pdf

Bell, M., Bush, D., Nicholson, P., O’Brien, D. \& Tran, T. (2002). Universities online: A survey of online education and services in Australia. Canberra, Occasional Paper Series, Higher Education Group, Commonwealth Department of Education, Science and Training.

http: / / www.dest.gov.au/highered / occpaper / 02a/02_a.pdf

Breen, R. (2001). Brookes Virtual evaluation, phase 1: Attitudes towards, and experience of, web-based learning amongst Oxford Brookes University staff. Oxford, Oxford Centre for Staff and Learning Development, Oxford Brookes University. http:/ / www.brookes.ac.uk/services/ocsd/5_research/bv/bvreport1.pdf

Brennan, R., McFadden, M. \& Law, E. (2001). All that glitters is not gold: Online delivery of education and training: Review of research. Adelaide, NCVER, under licence from ANTA.

Dearn, J., Fraser, K. \& Ryan, Y. (2002). Investigation into the provision of professional development for university teaching in Australia: A discussion paper. A HEIP DEST commissioned project, Commonwealth of Australia.

http:/ / www.dest.gov.au/highered/pubs/uni_teaching/uni_teaching.pdf

DEETYA (1998). Learning for life: Review of higher education financing and policy: Final report (the West Review). Canberra, Department of Employment, Education, Training and Youth Affairs.

http:/ / www.dest.gov.au/archive/highered/hereview/herr.pdf

Dooley, K.E. (1999). Towards a holistic model for the diffusion of educationa technologies:: An integrative review of educational innovation studies. Educational Technology \& Society, 2(4), 35-45.

http: / / ifets.ieee.org/periodical/vol_4_99/kim_dooley.pdf

Dooley, L., Metcalf, T. \& Martinez, A. (1999). A study of the adoption of computer technology by teachers. Educational Technology E Society, 2(4), 107-115. http:/ / ifets.ieee.org/periodical/vol_4_99/ldooley.pdf

Drysdale, J. \& Creanor, L. (1998). Leading new teachers to learning technology. In N. Mogey (Ed), Evaluation studies. Edinburgh, Learning Technology Dissemination Initiative, Heriot-Watt University, 13-18.

Ellis, D. (2002). Online learning a first for students. The Adelaidean, 11(1),1, 3. http:/ / www.adelaide.edu.au/pr/publications/ adelaidean/archive/Feb02.pdf 
Felix, U. (2002). [Reporting a keynote address to be given by Felix at the Languages, Linguistics and Area Studies in Higher Education conference in Manchester, England, June 2002]. The Australian, Higher Education Supplement: 50 .

Gribble, K. \& Ziguras, C. (2003). Learning to teach offshore: Pre-departure training for lecturers in transnational programs. Higher Education Research $\mathcal{E}$ Development, 22(2), 205-216.

Gruba, P. (2001). Developing staff IT skills in the arts. Meeting at the Crossroads. Proceedings of the 18th Annual Conference of the Australian Society for Computers in Learning in Tertiary Education (ASCILITE), Melbourne: Biomedical Multimedia Unit, The University of Melbourne, 225-233. http:// www.ascilite.org.au/conferences/melbourne01/pdf/papers/grubap.pdf

Guthrie, H. (2003). Online learning: Research readings. Adelaide, National Centre for Vocational Education Research.

Hansen, S. (2001). 'Power to the people': Ownership opportunities with web enabled IT. Proceedings Ausweb 2001, Coffs Harbour. [verified 24 Mar 2004] http:/ / ausweb.scu.edu.au/ aw01/ papers/ refereed/hansen/ paper.html

Hansen, S. \& Salter, G. (2001). The take-up of web technology: Promoting changes in teaching staff and in the institution. Flexible Learning for a Flexible Society, Proceedings of ASET-HERDSA 2000 Conference, Toowoomba, Qld, ASET and HERDSA, 319-325. [verified 24 Mar 2004] http:/ / www.aset.org.au/ confs/ asetherdsa2000/procs/hansen.html

Kearns, P. (2003). The partnership challenge: Some international perspectives on policy for information and communication technology in education. In $\mathrm{H}$. Guthrie (Ed), Online learning: Research findings. Adelaide, National Centre for Vocational Education Research, 41-52.

Learning and Teaching Development Unit (2003). Annual report, Learning and Teaching Development Unit, 2002. Adelaide, The University of Adelaide.

Lines, R. (2000). Teaching with technology: The space between strategy and outcomes. Ultibase archive, July. [verified 24 Mar 2004]

http: / / ultibase.rmit.edu.au/Articles/online/lines1.pd

McNaught, C., Phillips, R., Rossiter, D. \& Winn, J. (2000). Developing a framezork for a useable and useful inventory of computer-facilitated learning and support materials in Australian universities. Canberra, Evaluations and Investigations Programme Report 99/11, Higher Education Division, Department of Education, Training and Youth Affairs. http:/ / www.detya.gov.au/archive/highered/eippubs/eip99$11 /$ developframework.pdf

O'Hagan, C. (1999). Embedding ubiquitous use of educational technology: Is it possible, do we want it and, if so, how do we achieve it? Educational Technology $\mathcal{E}$ Society, 2(4), 19-22. http:/ /ifets.ieee.org/periodical/vol_4_99/introduction.pdf 
Oxford Brookes University (2002). Brookes Virtual evaluation: Phase 2 report. Oxford Centre for Staff and Learning Development, Oxford Brookes University. http:/ / www.brookes.ac.uk/services/ocsd/5_research/bv/bvreport2.pdf

Reid, A. (2002). Is there an 'ideal' approach for academic development? Spheres of Influence: Ventures and Visions in Educational Development. 4th World Conference of the International Consortium for Educational Development (ICED), Perth, Australia. http:/ / www.csd.uwa.edu.au/iced2002/ publication/Anna_Reid.pdf

Rumble, G. (2001). The costs and costing of networked learning. Journal of Asynchronous Learning Networks, 5(2), 75-96. http:/ / www.sloanc.org/publications / jaln/v5n2/pdf]/v5n2_rumble.pdf

Salter, G. \& Hansen, S. (1999). Modelling new skills for on-line teaching. Responding to diversity. Proceedings of the 16th annual Australian Society for Computers in Learning in Tertiary Education Conference, Queensland University of Technology, Brisbane, 301-305.

http: / / www.ascilite.org.au/conferences/brisbane99/ papers/ salterhansen.pdf

Sarris, A., Taplin, J. \& Reilly, M. (2003). University of Adelaide values survey. Adelaide, The University of Adelaide.

http: / / www.adelaide.edu.au/opd/about/ futuredirections/Report.pdf

Schifter, C.C. (2000). Faculty participation in asynchronous learning networks: A case study of motivating and inhibiting factors. Journal of Asynchronous Learning Networks, 4(1), 15-22. http:/ / www.aln.org/alnweb/journal/Vol4_issue1/schifter.pdf

Scribbins, J. (2002). The National Learning Network final report to the Evaluation Steering Group and the NLN Programme Board by the Learning and Skills Development Agency (LSDA) and Sheffield Hallam University. Learning and Skills Council. http:/ / www.nln.ac.uk/ uploadedfiles/NLN_FinalReport.pdf

SPSS Inc. (2002). Statistical Package for the Social Sciences, version 11.5.0 [statistical software package]. Chicago, Illinois, SPSS Inc.

The full report Factors influencing the adoption and use of web supported teaching by academic staff at the University of Adelaide is available from the corresponding author. Address for correspondence:

Susan Shannon

School of Architecture, Landscape Architecture and Urban Design

The University of Adelaide

South Australia 5005, Australia

Email: susan.shannon@adelaide.edu.au

Loene Doube

Learning and Teaching Development Unit

The University of Adelaide South Australia

Email: loene.doube@adelaide.edu.au 